\title{
Rapid identification of capsulated Acinetobacter baumannii using a density- dependent gradient test
}

\author{
Hadas Kon ${ }^{1}$, David Schwartz ${ }^{1}$, Elizabeth Temkin ${ }^{1}$, Yehuda Carmeli ${ }^{1,2}$ and Jonathan Lellouche ${ }^{1 *}$ (D)
}

\begin{abstract}
Background: Gram-negative bacterial capsules are associated with production of carbohydrates, frequently resulting in a mucoid phenotype. Infections caused by capsulated or mucoid A. baumannii are associated with increased clinical severity. Therefore, it is clinically and epidemiologically important to identify capsulated $A$. baumannii. Here, we describe a density-dependent gradient test to distinguish between capsulated and thin/noncapsulated A. baumannii.

Results: Thirty-one of 57 A. baumannii isolates displayed a mucoid phenotype. The density-dependent gradient test was comprised of two phases, with silica concentrations of 30\% (top phase) and 50\% (bottom phase). Twenty-three isolates migrated to the bottom phase, indicating thin or non-capsulated strains, and 34 migrated to the top phase, suggesting strains suspected to be capsulated. There was agreement between the mucoid and the non-mucoid phenotypes and the density-dependent gradient test for all but three isolates. Total carbohydrates extracted from strains suspected to be capsulated were significantly higher. Transmission electron microscopy confirmed the presence of a capsule in the six representative strains suspected to be capsulated.

Conclusions: The density-dependent gradient test can be used to verify capsule presence in mucoid-appearing $A$. baumannii strains. Identifying capsulated strains can be useful for directing infection control measures to reduce the spread of hypervirulent strains.
\end{abstract}

Keywords: Carbapenem-resistant Acinetobacter baumannii, Capsule, Mucoid phenotype, Hypervirulence

\section{Background}

Acinetobacter baumannii is a major cause of hospitalacquired infections [1]. A. baumannii virulence factors include siderophore-mediated iron acquisition systems, biofilm formation, motility, and a remarkable capacity to acquire and rearrange genetic determinants [2]. These virulence factors are involved in the pathobiology and infection process, such as binding to host epithelial cells, cellular damage, serum resistance, and invasion [3]. Surface

\footnotetext{
* Correspondence: jonathan|@tlvmc.gov.il

${ }^{1}$ National Institute for Antibiotic Resistance and Infection Control, Ministry of Health, Tel-Aviv Sourasky Medical Center, 6 Weizmann St, 6423906 Tel-Aviv, Israel

Full list of author information is available at the end of the article
}

carbohydrates are known to influence virulence and fitness of $A$. baumannii. These carbohydrates include capsular polysaccharides (capsule), lipooligosaccharide (LOS) and the exopolysaccharide poly- $\beta-(1-6)-\mathrm{N}$-acetylglucosamine (PNAG). While surface carbohydrates influence pathogenicity, studies show that the capsule is the predominant virulence factor in A. baumannii [4,5]. Capsules are highmolecular-weight hydrophilic polymers that form a layer enveloping the bacterial cell. In A. baumannii, capsules are composed of tightly packed repeating oligosaccharide subunits (K units), typically consisting of 4-6 sugars [5, 6]. Capsules provide a protective shield against immune recognition by limiting interactions between immunogenic surface structures of the pathogen and host defenses, 
leading to immune evasion and serum resistance [5]. In addition, capsule production contributes to anti-phagocytic and anti-bacteriolytic activity, as the negatively charged and unique surface of the capsule prevents phagocytes from adhering [7].

Few methods are available to quantify surface carbohydrates and to determine their composition. Carbohydrate quantification can be obtained by uronic acid assay [8] and composition can be assessed by nuclear magnetic resonance or liquid chromatography $[6,9]$. Clinical laboratories do not incorporate these methods because they are cumbersome and require hazardous materials.

Overproduction of surface carbohydrates comprising the bacterial capsule may result in a mucoid phenotype [10-12]. This phenotype may vary, depending on the growth medium, incubation time, and conditions [10-12]. The observed phenotype is subjective and difficult to determine by simple examination, thus requiring further confirmation. The string test is based on measuring the length of a thread-like mucoid that is formed from a loop drawn gradually away from the tested suspension. This test is commonly used by clinical laboratories for Klebsiella pneumoniae and Vibrio cholera isolates [13, 14]. Additionally, microscopy using India ink staining is performed to detect capsulated strains in K. pneumoniae and Streptococcus spp. [15]. No specific test exists to detect capsulated A. baumannii.

The density-dependent gradient method is a technique used to separate cells by size [16]. It is based on the migration of cells by centrifugation through a gradient matrix. The matrix is made up of multiple phases of an organic polymer, each phase consisting of a different polymer concentration, resulting in a gradient with various densities. This method is commonly used to purify different eukaryotic cell types [17], but is seldom used for bacteria. A few studies have used this method to separate strains of a specific bacteria based on capsule size [18-21]. Here, we describe a density-dependent gradient test that we developed to distinguish between capsulated and thin/non-capsulated A. baumannii using colloidal silica particles as a matrix.

\section{Results}

\section{Phenotype categorization}

Of the 57 A. baumannii isolates, 31 (54.4\%) displayed a mucoid phenotype and 26 (45.6\%) a non-mucoid phenotype (Table 1). Colonies of mucoid A. baumannii appeared moist, raised, and viscid with irregular margins, while non-mucoid strains displayed a typical phenotype of small, round, convex colonies with distinct margins. The control strain ATCC 19606 displayed a non-mucoid phenotype as expected. The two other control strains, a hypermucoid string test-positive $K$. pneumoniae (HM-
$\mathrm{KP}$ ) and a mucoid A. baumannii with a significant capsule and an extracellular slime (CAP-AB), displayed a mucoid phenotype as expected (Fig. 1).

\section{Determination of optimal parameters of the gradient composition}

The bacterial bands of HM-KP and CAP-AB migrated successfully into the silica concentrations of 20,30 and $40 \%(\mathrm{~V} / \mathrm{V})$ but were unable to penetrate the density of $50 \%$ or higher. Therefore, we selected $50 \%$ as the maximum phase concentration of the gradient matrix. The band of the non-mucoid control (ATCC 19606) migrated in a concentration range of $20-70 \%$. The $20 \%$ concentration was rejected because the band settled at the bottom of the tube. Therefore, $30 \%$ was the minimum silica concentration of the phase range that a non-mucoid control strain could penetrate and be easily visualized. Thus, $30 \%$ was selected as the minimal phase concentration. The four mucoid and the two non-mucoid representative isolates displayed similar results to HM-KP/CAP-AB and ATCC 19606, respectively (Table 1 ). Thus, for our sample and validation settings, the range of work was 30-50\% (Fig. 2).

The final configuration of our test was a matrix with a volume of $2 \mathrm{~mL}$ composed of a 30\% top phase $(1 \mathrm{~mL})$ and a $50 \%$ bottom phase $(1 \mathrm{~mL})$. After the addition of the bacterial inoculum $(600 \mu \mathrm{L})$ and centrifugation, an isolate was suspected to be capsulated if the band migrated within $0-16 \mathrm{~mm}$ (top phase). Isolates were considered thin or non-capsulated if the band migrated to $>16 \mathrm{~mm}$ (bottom phase) (Fig. 3a). In this configuration, it is not possible to distinguish between an isolate with a thin capsule and a non-capsulated isolate, since they both migrate to the bottom phase.

\section{Density-dependent gradient test}

Twenty-three of the 57 isolates (40.4\%) migrated to the bottom phase, indicating thin or non-capsulated strains. Thirty-four isolates (59.6\%) migrated within the top phase and were suspected to be capsulated (Fig. 3b and Table 1). For 54 isolates (94.7\%), there was complete agreement between the density-dependent gradient test results and the phenotype determination. Three isolates (5.3\%) exhibiting a non-mucoid phenotype were classified as capsulated by the density-dependent gradient test (isolates AB24, AB25, AB26). The strains used as controls exhibited expected results: HM-KP and CAP-AB displayed a band in the top phase, while ATCC 19606 migrated to the bottom phase (Fig. 3b).

One strain initially exhibited a band in both the top phase and the bottom phase, suggesting the presence of two different strains. Following further isolation, both strains were identified as $A$. baumannii (AB41 and AB20). Strain AB41 appeared to be mucoid and its band was observed on the top phase of the gradient, while 
Table 1 Characteristics of mucoid and non-mucoid A. baumannii isolates and summary of results

\begin{tabular}{|c|c|c|c|c|c|c|}
\hline & Sample & Origin & Clonal complex ${ }^{1}$ & $\begin{array}{l}\text { Density-dependent } \\
\text { gradient }^{2}\end{array}$ & $\begin{array}{l}\text { Total carbohydrates } \\
(\mu \mathrm{g} / \mathrm{mL})\end{array}$ & $\begin{array}{l}\text { Capsule thickness } \\
(\mathrm{nm})^{3}\end{array}$ \\
\hline \multirow[t]{27}{*}{ Non-mucoid ${ }^{4}$} & $\mathrm{AB} 01$ & Sputum & ST3 & Non-capsulated $^{7}$ & $44.0 \pm 1.67$ & - \\
\hline & AB02 & Blood & ST3 & Non-capsulated & $35.3 \pm 0.79$ & - \\
\hline & $\mathrm{ABO3*}$ & Blood & ST2 & Non-capsulated & $53.7 \pm 2.45$ & - \\
\hline & AB04 & Rectal & ST3 & Non-capsulated & $74.8 \pm 2.27$ & - \\
\hline & AB05 & Skin & $\mathrm{ST} 3$ & Non-capsulated & $83.7 \pm 2.11$ & - \\
\hline & AB06 & Blood & $\mathrm{N} / \mathrm{D}^{5}$ & Non-capsulated & $66.5 \pm 1.39$ & - \\
\hline & AB07 & Blood & $\mathrm{N} / \mathrm{D}$ & Non-capsulated & $84.5 \pm 2.24$ & - \\
\hline & AB08 & Blood & ST2 & Non-capsulated & $75.9 \pm 1.24$ & - \\
\hline & AB09 & Sputum & ST3 & Non-capsulated & $39.0 \pm 10.81$ & - \\
\hline & $A B 10^{*}$ & Blood & N/D & Non-capsulated & $43.1 \pm 2.20$ & - \\
\hline & AB11 & Sputum & ST3 & Non-capsulated & $54.8 \pm 2.02$ & 0 \\
\hline & $\mathrm{AB} 12$ & Blood & ST2 & Non-capsulated & $55.2 \pm 1.56$ & - \\
\hline & AB13 & Blood & N/D & Non-capsulated & $64.5 \pm 2.01$ & - \\
\hline & AB14 & Rectal & ST2 & Non-capsulated & $63.6 \pm 1.78$ & - \\
\hline & AB15 & Skin & ST2 & Non-capsulated & $84.4 \pm 2.54$ & - \\
\hline & AB16 & Blood & ST2 & Non-capsulated & $72.3 \pm 1.56$ & - \\
\hline & AB17 & Blood & ST3 & Non-capsulated & $64.4 \pm 2.27$ & - \\
\hline & AB18 & Blood & N/D & Non-capsulated & $45.0 \pm 1.56$ & - \\
\hline & AB19 & Pus & ST2 & Non-capsulated & $56.6 \pm 1.65$ & - \\
\hline & AB20 & Blood & ST3 & Non-capsulated & $65.4 \pm 2.43$ & - \\
\hline & AB21 & Blood & $\mathrm{N} / \mathrm{D}$ & Non-capsulated & $28.0 \pm 4.15$ & - \\
\hline & AB22 & Skin & ST2 & Non-capsulated & $49.1 \pm 1.79$ & - \\
\hline & AB23 & Wound & ST2 & Non-capsulated & $51.5 \pm 1.59$ & - \\
\hline & AB24 & Sputum & ST3 & Capsulated & $254.3 \pm 5.65$ & - \\
\hline & AB25 & Sputum & ST3 & Capsulated & $262.2 \pm 12.2$ & - \\
\hline & AB26 & Blood & ST3 & Capsulated & $257.8 \pm 5.48$ & - \\
\hline & ATCC $19606^{*}$ & Urine & ST52 & Non-capsulated & $34.5 \pm 1.66$ & 0 \\
\hline \multirow[t]{16}{*}{ Mucoid $^{4}$} & AB27 & Skin & ST3 & Capsulated & $212.8 \pm 8.77$ & - \\
\hline & AB28 & Skin & ST3 & Capsulated & $426.5 \pm 6.39$ & - \\
\hline & $A B 29^{*}$ & Blood & ST3 & Capsulated & $356.4 \pm 4.61$ & - \\
\hline & AB30 & Wound & ST3 & Capsulated & $351.2 \pm 5.44$ & - \\
\hline & AB31 & Blood & ST3 & Capsulated & $191.4 \pm 6.14$ & - \\
\hline & AB32 & Sputum & ST3 & Capsulated & $240.0 \pm 14.97$ & - \\
\hline & AB33 & Skin & ST3 & Capsulated & $412.0 \pm 9.25$ & - \\
\hline & AB34* & Skin & ST3 & Capsulated & $356.8 \pm 7.85$ & $92 \pm 8$ \\
\hline & AB35 & Blood & ST3 & Capsulated & $317.3 \pm 8.51$ & - \\
\hline & AB36 & Rectal & ST3 & Capsulated & $286.7 \pm 8.98$ & - \\
\hline & AB37 & Rectal & ST3 & Capsulated & $290.6 \pm 9.44$ & - \\
\hline & AB38 & Blood & ST3 & Capsulated & $166.7 \pm 7.59$ & - \\
\hline & AB39 & Blood & ST3 & Capsulated & $275.2 \pm 6.66$ & - \\
\hline & AB40 & Sputum & ST2 & Capsulated & $319.4 \pm 9.78$ & - \\
\hline & AB41 & Blood & ST3 & Capsulated & $132.9 \pm 7.32$ & - \\
\hline & AB42 & Skin & ST3 & Capsulated & $338.4 \pm 11.11$ & - \\
\hline
\end{tabular}


Table 1 Characteristics of mucoid and non-mucoid A. baumannii isolates and summary of results (Continued)

\begin{tabular}{|c|c|c|c|c|c|}
\hline Sample & Origin & Clonal complex ${ }^{1}$ & $\begin{array}{l}\text { Density-dependent } \\
\text { gradient }^{2}\end{array}$ & $\begin{array}{l}\text { Total carbohydrates } \\
(\mu \mathrm{g} / \mathrm{mL})\end{array}$ & $\begin{array}{l}\text { Capsule thickness } \\
(\mathrm{nm})^{3}\end{array}$ \\
\hline AB43 & Blood & ST3 & Capsulated & $247.4 \pm 7.40$ & $122 \pm 6$ \\
\hline AB44 & Blood & ST3 & Capsulated & $261.0 \pm 5.58$ & $92 \pm 13$ \\
\hline$A B 45^{*}$ & Blood & N/D & Capsulated & $207.7 \pm 5.39$ & - \\
\hline AB46 & Blood & ST3 & Capsulated & $364.7 \pm 16.48$ & - \\
\hline AB47 & Wound & ST3 & Capsulated & $316.6 \pm 8.47$ & - \\
\hline$A B 48^{*}$ & Blood & $\mathrm{ST} 3$ & Capsulated & $174.9 \pm 40.31$ & - \\
\hline AB49 & Wound & N/D & Capsulated & $157.6 \pm 6.37$ & - \\
\hline AB50 & Tracheal aspirate & N/D & Capsulated & $226.5 \pm 17.51$ & - \\
\hline AB51 & Tracheal aspirate & N/D & Capsulated & $254.1 \pm 9.04$ & - \\
\hline AB52 & Tracheal aspirate & N/D & Capsulated & $182.2 \pm 9.45$ & - \\
\hline AB53 & Sputum & ST3 & Capsulated & $264.2 \pm 13.25$ & - \\
\hline AB54 & Sputum & ST3 & Capsulated & $353.4 \pm 15.07$ & - \\
\hline AB55 & $\mathrm{BAL}^{6}$ & N/D & Capsulated & $132.3 \pm 12.64$ & - \\
\hline AB56 & Sputum & N/D & Capsulated & $118.5 \pm 16.17$ & - \\
\hline AB57 & Sputum & N/D & Capsulated & $130.7 \pm 10.01$ & - \\
\hline CAP-AB* & Blood & ST3 & Capsulated & $290.6 \pm 9.53$ & $96 \pm 11$ \\
\hline HM-KP* & Liver Abscess & K1 & Capsulated & - & - \\
\hline
\end{tabular}

${ }^{1}$ Pasteur scheme; ${ }^{2}$ Length of migration: thin or non-capsulated if $>16 \mathrm{~mm}$, suspected as capsulated if $0-16 \mathrm{~mm} ;{ }^{3}$ Determined by TEM; ${ }^{4}$ Determined by visual observation; ${ }^{5}$ Not determined; ${ }^{6}$ Bronchoalveolar lavage; ${ }^{7}$ Non-capsulated refers to an isolate with a thin capsule or no capsule; ${ }^{*}$ Isolates used for validation of the density-dependent gradient test

strain AB20 displayed a non-mucoid phenotype and migrated to the bottom phase, signifying that it was thin/non-capsulated (Fig. 4). Molecular genotyping suggested that both isolates were identical and harbored a bla $a_{\text {OXA-374 }}$ gene, a variant of the bla $a_{\text {OXA-71-LIKE }}$ gene. The distinct capsular phenotypes of different colonies of this strain may be due to phase variation.

When we repeated the density-dependent gradient test using isolates taken directly from agar plates, the phenotypes were identical to those obtained from the isolates prepared from brain heart infusion broth (BHI), including the three isolates that exhibited discrepancies (AB24, AB25, AB26).

\section{Carbohydrate production}

In order to confirm capsule presence, we quantified the total polysaccharides present in the bacterial cell, including capsular polysaccharides and LOS. Among the 23

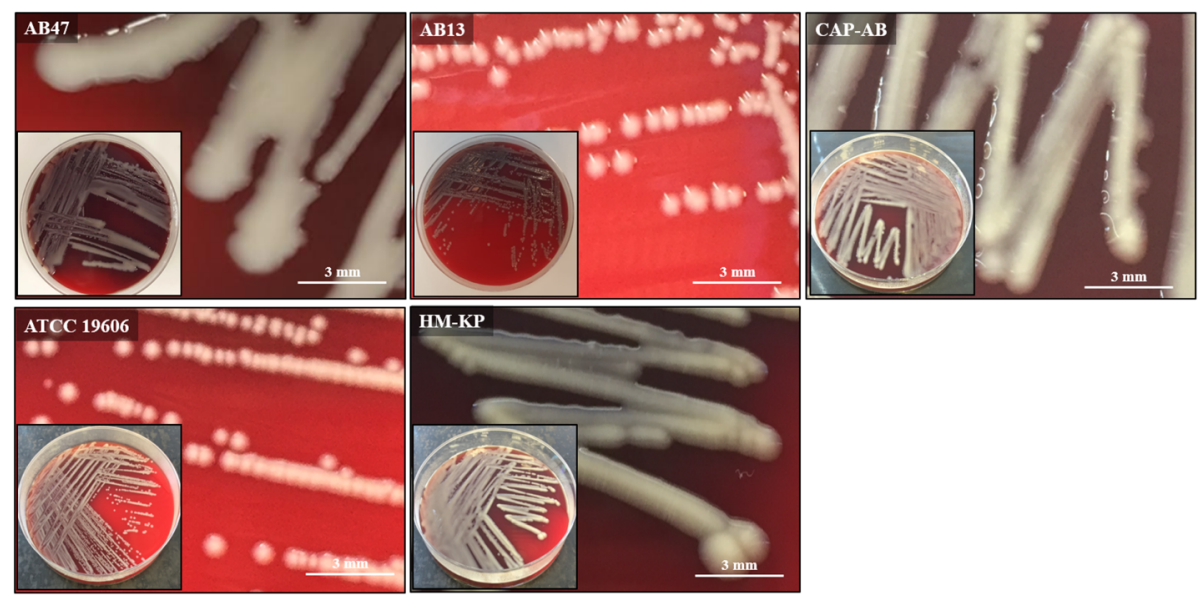

Fig. 1 Phenotype of mucoid and non-mucoid isolates. Representative A. baumannii isolates with a mucoid (AB47) and a non-mucoid phenotype (AB13) observed on blood agar, following $18 \mathrm{~h}$ aerobic incubation at $35 \pm 2{ }^{\circ} \mathrm{C}$. The CAP-AB (capsulated and mucoid A. baumannii), ATCC 19606 and HM-KP (hypermucoid string test-positive K. pneumoniae) were used as controls 


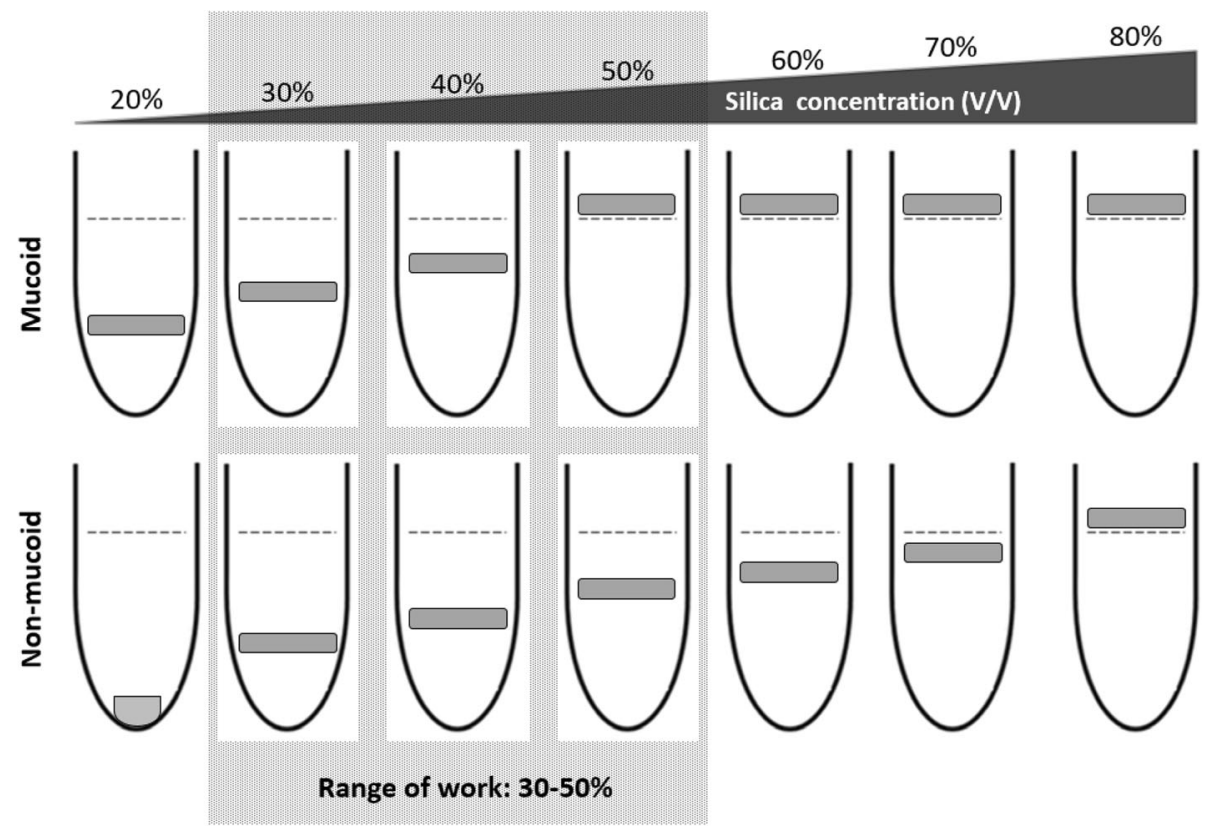

Fig. 2 Validation of gradient composition. Schematic illustration of the method used to determine the optimal parameters of the gradient composition and the adequate range of work (box with dashed gray background). The range of work was determined by testing a panel of seven single silica concentrations (20-80\% VN). The validation was performed on three control strains (CAP-AB, HM-KP, ATCC 19606) and confirmed on six isolates selected randomly from the sample. The grey square illustrates a band of bacterial cells following centrifugation. The dashed line represents the upper liquid level of the silica sample

isolates classified as non-mucoid and thin/non-capsulated, the mean value of total carbohydrates was $58.9 \pm$ $2.4 \mu \mathrm{g} / \mathrm{mL}$. The carbohydrate amount measured for ATCC 19606 fell in this range $(34.5 \pm 1.7 \mu \mathrm{g} / \mathrm{mL})$. In contrast, among the isolates that were mucoid and suspected to be capsulated, the mean carbohydrate amount was $260.0 \pm 10.3 \mu \mathrm{g} / \mathrm{mL}$. The value of total carbohydrates measured for CAP-AB fell in this range $(290.6 \pm 9.5 \mu \mathrm{g} /$ $\mathrm{mL})$. The difference between the thin/non-capsulated group and the group suspected to be capsulated was significant $(P<0.001)$. The carbohydrate amounts for the three isolates with discrepant phenotypes (mucoidicity and density-dependent gradient) were similar to the isolates suspected to be capsulated: $254.3 \pm 5.7,262.2 \pm 12.2$ and $257.8 \pm 5.5 \mu \mathrm{g} / \mathrm{mL}$ (Fig. 5 and Table 1).

\section{Transmission electron microscopy (TEM) results}

The presence of capsules was confirmed by TEM imaging. We analyzed three isolates that were mucoid and likely capsulated. All three displayed a significant polysaccharide matrix that was physically associated with the cell surface. The capsule was clearly visible as a light grey halo surrounding the outer membrane of the bacterial cell, associated with filaments of extracellular polysaccharides (Fig. 6). The mean capsule thickness of each isolate was $92 \pm 8$ (AB34), $92 \pm 13$ (AB44) and $122 \pm 6$ $\mathrm{nm}$ (AB43). The range of thickness values for all three isolates overlapped the range of capsule thickness of
CAP-AB (96 $\pm 11 \mathrm{~nm})$ (Fig. 6). No capsule was visible in the images of an isolate classified as non-mucoid by phenotype and thin/non-capsulated by the densitydependent gradient test. No capsule was visible in ATCC 19606, but fibers were observed in the background of the images, most likely representing artifact from sample preparation (Fig. 6 and Table 1). The difference in capsule thickness between the thin/non-capsulated group and the group suspected to be capsulated was significant $(P<0.001)$. Capsule presence was confirmed by India ink staining. The cells appeared purple surrounded by a clear halo on a dark background, indicating a capsule, similar to the CAP-AB isolate. No halo was observed for the thin-capsulated ATCC 19606 (data not shown).

\section{Capsule visualization in isolates with a discrepancy between phenotype and the density-dependent gradient test}

For the three isolates with a non-mucoid phenotype but suspected to be capsulated according to the densitydependent gradient test (AB24, AB25, AB26), capsule presence was confirmed by India ink staining. A significant capsule was observed for $\mathrm{CAP}-\mathrm{AB}$, while no capsule was detected for ATCC 19606 (Fig. 7).

\section{Discussion}

To our knowledge, this is the first report of a simple method to confirm capsulated A. baumannii based on 
A

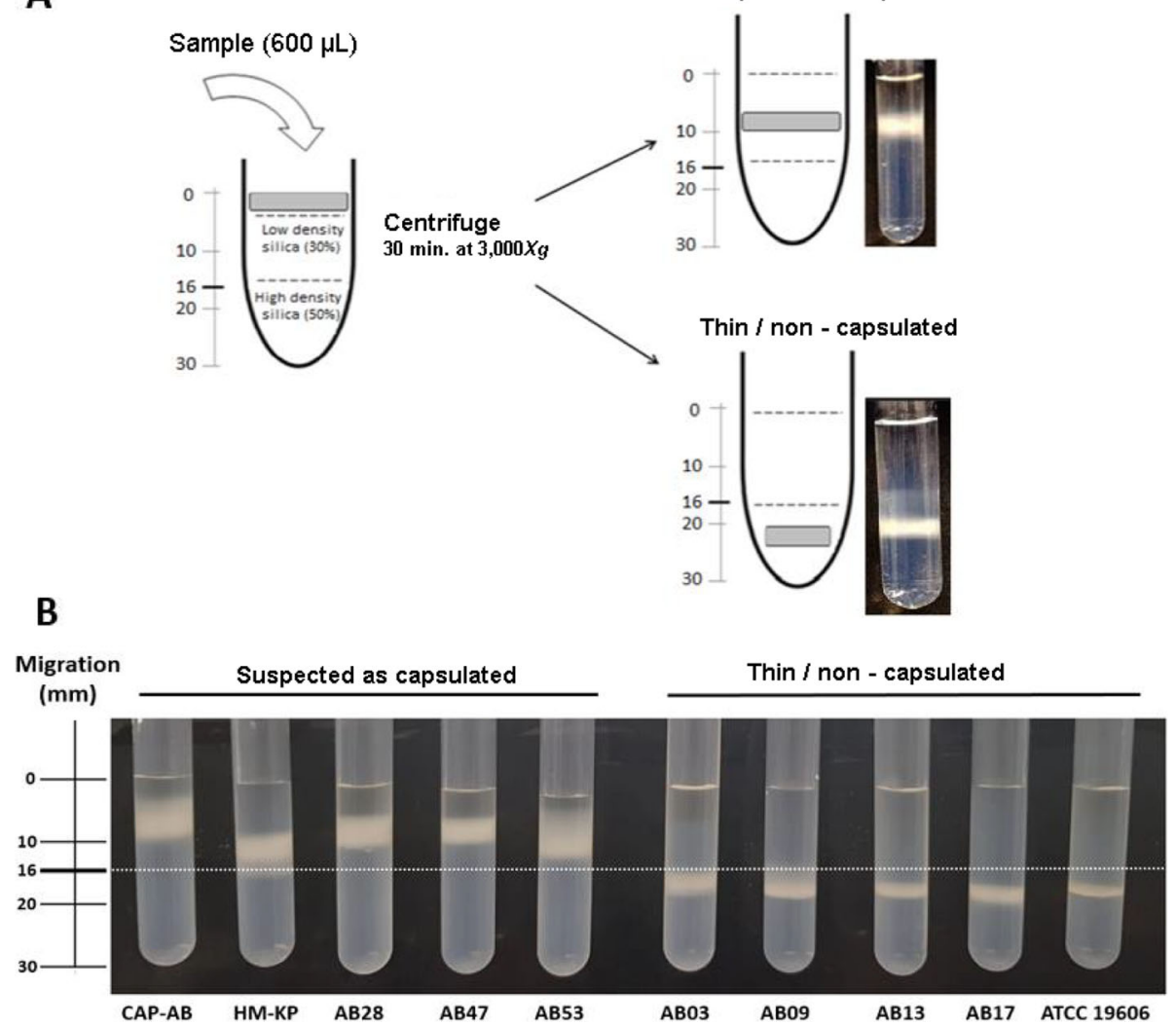

Suspected as capsulated

Fig. $\mathbf{3}$ a Schematic illustration of the density-dependent gradient test. Bacterial cells (gray square) are applied to the top of a gradient matrix fixed in two phases (30 and 50\% silica concentration). Following centrifugation, the bacterial cells migrate to either the top phase of the gradient ( 0 to $16 \mathrm{~mm}$ ), indicating that the strain may be capsulated, or to the bottom phase $(>16 \mathrm{~mm}$ ), indicating a thin or non-capsulated strain. $\mathbf{b}$ Density-dependent gradient test results. On the left are the two capsulated control strains (CAP-AB and HM-KP) and three representative isolates suspected to be capsulated, with bacterial bands in the top phase $(0-16 \mathrm{~mm})$. On the right is the control strain ATCC 19606 and four representative thin/non capsulated isolates with bands in the bottom phase (>16 mm)

density-dependent gradient testing. We validated our method by comparing the results to TEM imaging and measurement of carbohydrate production. Our test can verify the presence of a capsule in suspected isolates exhibiting a mucoid phenotype. The test can also detect capsulated strains that do not exhibit a mucoid phenotype.
Furthermore, isolates with a heterogeneous production of capsules can be detected using this test. Phase variation, a known phenomenon in A. baumannii, modulates capsule exopolysaccharides as well as other phenotypes such as motility, cell shape, biofilm formation, antimicrobial resistance, and virulence [11, 22].
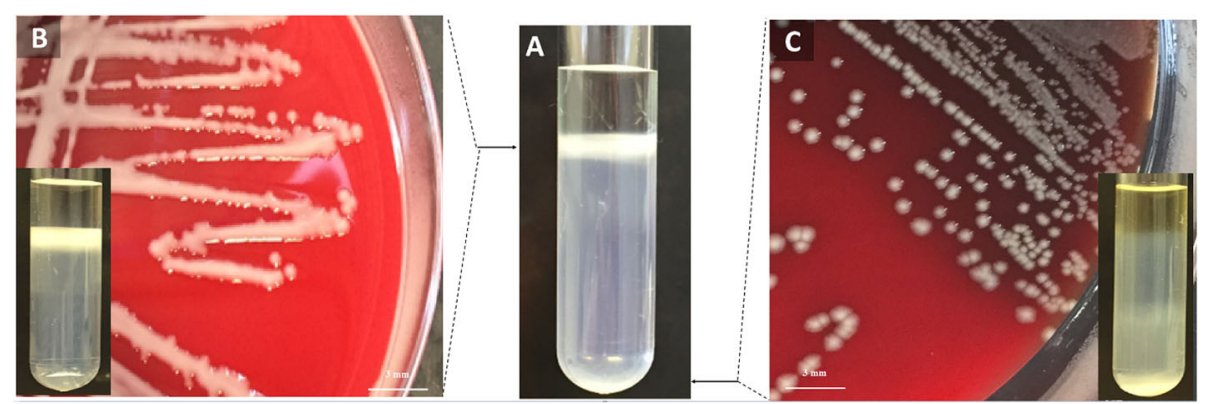

Fig. 4 Heterogeneous culture. a Density-dependent gradient test of a heterogeneous culture with bacterial bands in both the top and bottom phases. $\mathbf{b}$ Isolate AB41 with a mucoid phenotype and its density-dependent gradient test (insert in B) with a single band in the top phase. $\mathbf{c}$ Isolate AB20 with a non-mucoid phenotype and its density-dependent gradient test (insert in C) with a single band settled in the bottom phase 


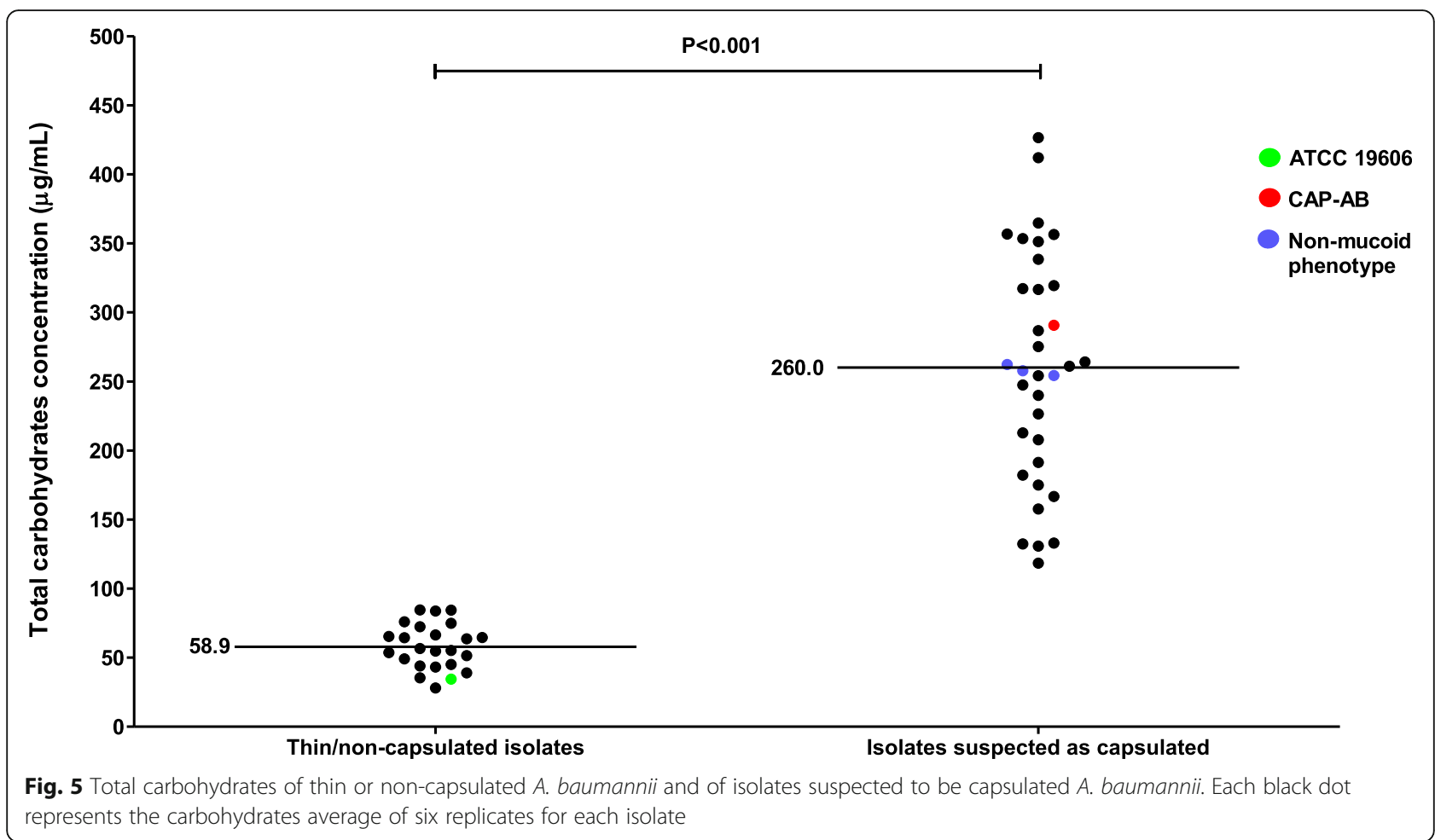

India ink staining is commonly used in clinical microbiology laboratories for capsule visualization. However, this method is labor intensive and requires two hours to prepare a sample. In comparison, our test is quick: a sample can be prepared in a few minutes and results can be read after $30 \mathrm{~min}$.

Identifying capsulated and mucoid A. baumannii is clinically and epidemiologically important because the presence of a capsule is associated with virulence. The role of capsules in virulence mechanisms and clinical outcomes is well known for K. pneumoniae [10, 23, 24], while data are limited for A. baumannii $[5,11]$. Only two studies linked A. baumannii mucosity and capsule formation to clinical severity and epidemic potential of the strains $[12,25]$.

Our study has some limitations. First, for simplicity, and in order to reduce the time required to prepare and perform this test, we used a two-phase gradient matrix. Due to this configuration, it is not possible to distinguish between an isolate with a thin capsule and a non-capsulated isolate, since they both migrate to the bottom phase. Higher resolution may have been achieved by adding more phases. Second, results can be influenced by changes in cell density due to different growth conditions, such as media type, temperature, presence of $\mathrm{CO}_{2}$ or presence of antibiotics. Third, we did not evaluate the impact of centrifugation time and centrifugal force on the test results.

\section{Conclusions}

Density-dependent gradient testing is a rapid, simple-toperform, and objective method for confirming capsulated A. baumannii. This method can be easily applied for suspected strains with a mucoid phenotype. Identifying capsulated and hypervirulent strains is important for clinical care and for outbreak investigations, for which it may help direct infection control measures.

\section{Methods}

Sample and phenotype determination

A total of 57 unrelated non- duplicate A. baumannii isolates from different hospitalized patients were selected randomly from the collection at the National Center for Infection Control and Antibiotic Resistance in Israel. The sample was composed of isolates collected from 15 medical centers from Israel and Europe in the years 20082019. The specimens were isolated from blood $(n=25)$, sputum $(n=11)$, skin $(n=8)$, rectum $(n=4)$, tracheal aspirate/bronchoalveolar lavage $(n=4)$ and other sites $(n=5)$. The isolates were identified to the species level by VITEK $^{\oplus}$ MS (bioMérieux SA, Marcy l'Etoile, France). Further confirmation of the species was performed by molecular genotyping using methods described by Evans et al. [26]. In brief, typing of $A$. baumannii isolates was conducted by the alignment of OXA-51-like $\beta$-lactamase sequence relationships using OXA-69A and OXA-69B primers. Clonality was determined by sequencing of the 

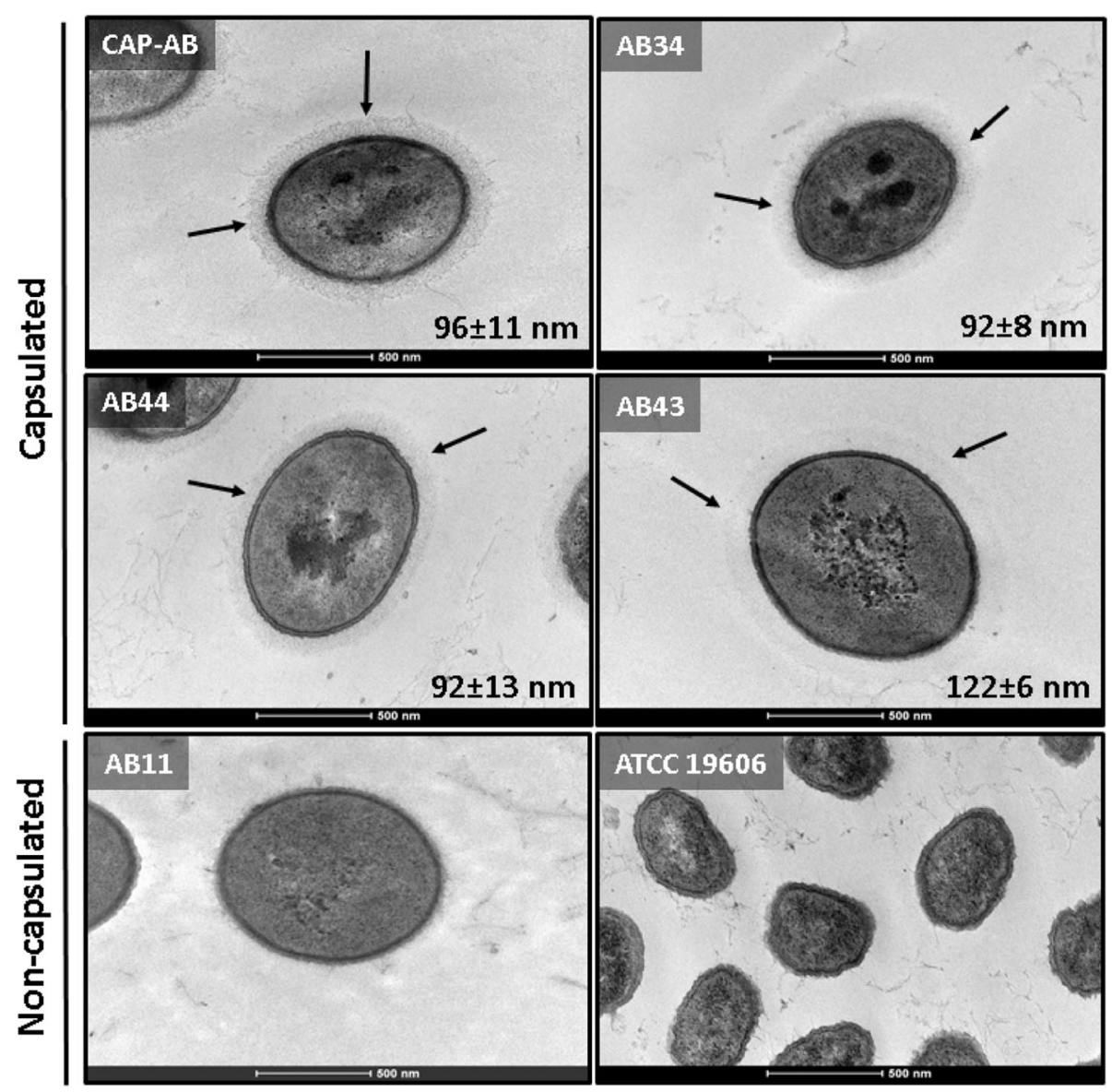

Fig. 6 Capsule thickness. TEM images of capsulated control strain CAP-AB, representative capsulated isolates (AB34, AB44, AB43), a representative noncapsulated isolate (AB11), and thin-capsulated control strain ATCC 19606. The halo surrounding the cells of the capsulated isolates represents the capsule (black arrows). The numbers indicate the mean capsule thickness (nm) and standard deviation Magnification: 43000 X. scale bar: 500 nm
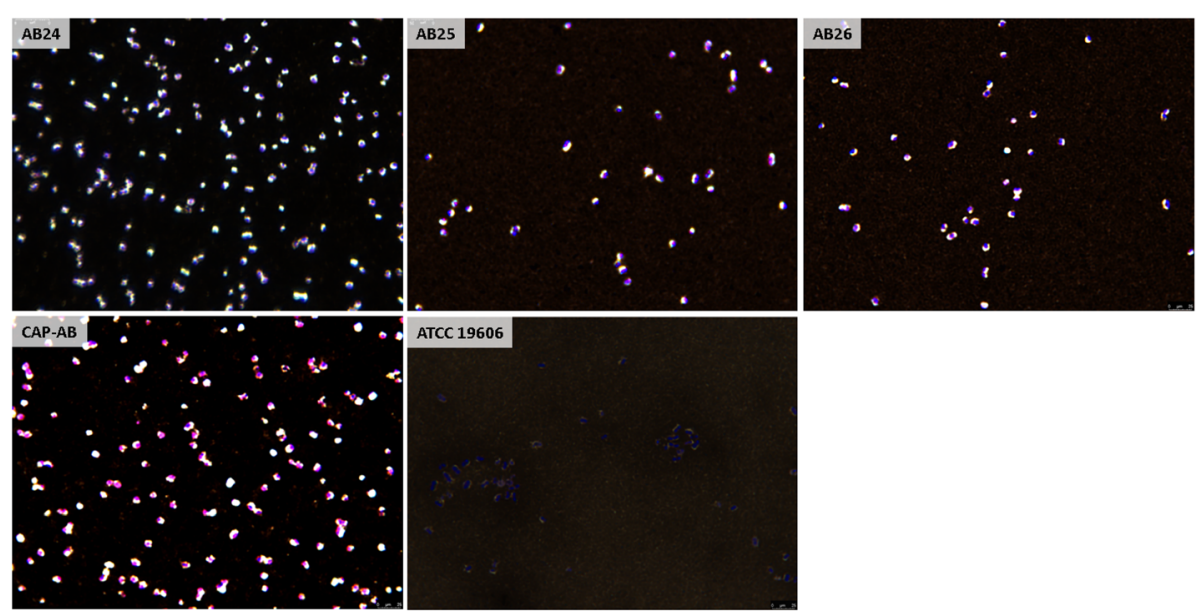

Fig. 7 Capsule visualization of the isolates with a non-mucoid phenotype but capsulated according to the density-dependent gradient test. Brightfield microscopy of isolates AB24, AB25, AB26, CAP-AB and ATCC 19606, stained by India ink and crystal violet. Capsule was visible as a clear halo

surrounding bacterial cell stained in violet. Images depict the trend observed in three different blood agar plates inoculated with the same isolate 
OXA-51-like gene to assign isolates to international clonal complexes [27]. Of the 57 isolates, ten belonged to clonal complex 2, 33 isolates belonged to clonal complex 3, and 14 belonged to other clonal complexes (Table 1).

All isolates were categorized by phenotype observation as mucoid or non-mucoid. Phenotype was determined following overnight incubation at $35 \pm 2{ }^{\circ} \mathrm{C}$ on blood agar (tryptic soy agar supplemented with 5\% sheep blood; Hylabs, Rehovot, Israel). Three clinical microbiologists evaluated the phenotype according to several colony morphology parameters, including texture, elevation, margin, size and shape [28]. If the categorization by the three microbiologists was not identical, the isolate was excluded (Table 1).

We also included in the sample three well-characterized specimens as controls: (i) a non-mucoid and thincapsulated A. baumannii (ATCC 19606); (ii) a mucoid $A$. baumannii with a significant capsule (CAP-AB). This isolate harbors a capsule locus type KL17 including wza-c genes and three different glycosyltransferases gtr38, 39, 40. (iii) A hypermucoid string test-positive $K$. pneumoniae (HM-KP).

All isolates were stored at $-80^{\circ} \mathrm{C}$ before sub-culturing and analysis.

\section{Principle of the density-dependent gradient method}

The method is based on bacterial cells passing through a gradient matrix as a result of centrifugal force. The gradient was composed of multiple phases, each phase with a different concentration $(20-80 \% \mathrm{~V} / \mathrm{V})$ of colloidal silica particles of $15-30 \mathrm{~nm}$ (Percoll, GE Healthcare, Uppsala, Sweden). Bacterial cells were inoculated to the top of a gradient and, due to centrifugation, migrated to different locations within the density gradient based on capsule size. This method assumes that cell size is similar between $A$. baumannii strains.

\section{Validation of gradient composition}

The validation was first performed on the three control strains and then confirmed on six isolates selected randomly from the sample: four with a mucoid phenotype and two with a non-mucoid phenotype. The nine isolates were prepared by inoculating a single colony in 10 $\mathrm{mL}$ BHI (Hylabs, Rehovot, Israel). The cultures were incubated for $18 \mathrm{~h}$ at $35 \pm 2{ }^{\circ} \mathrm{C}$ with shaking (250 rpm), to reach a stationary growth phase (final normalized optical density $\mathrm{OD}_{600}$ of $0.7-0.9$ ). The cultures were centrifuged for $10 \mathrm{~min}$ at $3200 \times \mathrm{g}$ and the bacterial cell pellet was resuspended with sterile phosphate buffer saline (PBS; BioLab, Jerusalem, Israel) to a final volume of $2 \mathrm{~mL}$.

In order to achieve robust separation and easy visualization of bacteria in the gradient matrix, we determined the optimal silica concentrations of the phases and the minimum number of phases required. To determine the optimal silica concentrations, a panel of seven single concentrations of silica $(20,30,40,50,60$, $70,80 \% \mathrm{~V} / \mathrm{V}$ ) with a final volume of $500 \mu \mathrm{L}$ were prepared. An aliquot of $100 \mu \mathrm{L}$ of each of the nine isolates was placed on the top of each tube and was centrifuged for $10 \mathrm{~min}$ at $8000 \times g$. The migration of the bacterial band was visually examined in the seven tubes and concentrations with bands that yielded a clear band within the gradient, without any smears, were selected. We rejected tubes in which bacterial cells could not penetrate the matrix or bacterial bands had settled at the bottom of the tube. The minimum and maximum silica concentrations of the remaining tubes composed the range of work.

\section{Gradient matrix preparation}

The matrix was prepared as follows: $1 \mathrm{~mL}$ of the lower density silica concentration was placed in an empty round-bottom tube $(12 / 75 \mathrm{~mm}$, Heinemann Labortechnik $\mathrm{GmbH}$, Duderstadt, Germany). Using a disposable syringe (23G needle), $1 \mathrm{~mL}$ of the higher density concentration was inserted at the bottom of the tube, allowing the lower density concentration to rise above it.

\section{Sample preparation and analysis}

We used two techniques to prepare the samples: (i) bacterial cells from BHI broth as described above in the "validation of gradient composition" section. Following centrifugation, the cell pellet was re-suspended for a final volume of $1 \mathrm{~mL}$. (ii) Bacterial cells directly from plate: a $5 \mu \mathrm{L}$ loop-load of colonies from an overnight incubation on blood agar $\left(35 \pm 2{ }^{\circ} \mathrm{C}\right)$ was suspended in 1 $\mathrm{mL}$ PBS. In order to evaluate whether the growth media affected the results, all tests were performed in duplicates from BHI broth and from blood agar plates.

An aliquot $(600 \mu \mathrm{L})$ of the bacterial cells was inoculated to the top of the gradient matrix. Following centrifugation for $30 \mathrm{~min}$ at $3000 \times g$, results were read by measuring the height of the bacterial band from the liquid level down to the middle of the bacterial band. A bacterial band that migrated to the bottom phase of the gradient was classified as a thin or non-capsulated strain, while a bacterial band that concentrated in the top phase was suspected to be a capsulated strain.

\section{Total carbohydrate quantification}

This test is based on the reaction of carbohydrates with sulfuric acid, which produces furfural derivatives that develop a detectible color when reacting with phenol $[29,30]$. The test quantifies the total polysaccharides present in the bacterial cell, including capsular polysaccharides and LOS. Extraction was performed by centrifuging $1 \mathrm{~mL}$ of a culture for $5 \mathrm{~min}$ at $14,500 \times g$ and washing the cells with $1 \mathrm{~mL}$ of $50 \mathrm{mM} \mathrm{NaCl}$ five times. During the 
last washing cycle, the cells were re-suspended in $50 \mathrm{mM}$ ethylenediaminetetraacetic acid to normalize the solution to $\mathrm{OD}_{600} 2.0$. The sample was incubated at $35 \pm 2{ }^{\circ} \mathrm{C}$ for 1 $\mathrm{h}$ in order to release the polysaccharides from the cell. Following centrifugation, $200 \mu \mathrm{L}$ of the supernatant of each isolate was used for quantification. A range of known sucrose/fructose $(1: 1 \mathrm{~W} / \mathrm{W})$ concentrations $(0-240 \mu \mathrm{g} / \mathrm{mL})$ was used to construct a standard curve. $200 \mu \mathrm{L}$ of $5 \%$ phenol (in water) and $1 \mathrm{~mL}$ of $93 \%$ sulfuric acid were added to the samples and to the standards. Furfural derivatives were measured by optical absorbance at $490 \mathrm{~nm}\left(\mathrm{OD}_{490}\right)$ after $10 \mathrm{~min}$. The total carbohydrate amount was calculated from the standard curve.

\section{Tem}

Six isolates selected randomly from the sample were imaged: one isolate determined to be thin or noncapsulated by the density-dependent gradient test, three isolates suspected to be capsulated by the densitydependent gradient test, and the two A. baumannii controls. The samples were prepared according to a standard protocol [31]. An aliquot of $1 \mathrm{~mL}$ of a culture grown overnight in $\mathrm{BHI}$ medium at $35 \pm 2{ }^{\circ} \mathrm{C}$ with shaking was centrifuged and the supernatant was removed manually. The bacterial cells pellet was re-suspended and fixed for $3 \mathrm{~h}$ in Karnovsky mixture [31]. To remove fixative residues, the cells were washed three times with $0.1 \mathrm{M}$ sodium cacodylate buffer. The cells were post-fixed in $1 \% \mathrm{OsO}_{4}, 0.5 \% \mathrm{~K}_{2} \mathrm{Cr}_{2} \mathrm{O}_{7}, 0.5 \% \mathrm{~K}_{4}\left[\mathrm{Fe}(\mathrm{CN})_{6}\right]$ and stained with $2 \%$ uranyl-acetate. The samples were washed with distilled water, dehydrated using ethanol and embedded with resin (Epon EMBED 812, EMS, Hatfield, PA) and polymerized at $60^{\circ} \mathrm{C}$ for $24 \mathrm{~h}$. Ultrathin sections (90-70 nm) were obtained using an ultra-microtome (EM UC7, Leica Biosystems, Buffalo Grove, IL). Samples were imaged using a TEM at $120 \mathrm{kv}$ (G-12 Spirit, FEI, Hillsboro, OR). Capsule thickness was determined by measuring five different sites on each isolate. For each isolate, the mean and standard deviation of the five measurements were calculated.

\section{India ink staining}

The samples were prepared according a standard protocol [15]. Briefly, a drop of India ink (Black 17, Pelikan, Hannover, Germany) was placed on a microscope slide and mixed with a colony from an overnight culture on blood agar. The slide was then dried under air at room temperature for $30 \mathrm{~min}$. The slide was saturated with $1 \%$ crystal violet (Merck, Rehovot, Israel) for $1 \mathrm{~min}$, rinsed with deionized water and dried under air at room temperature for $2 \mathrm{~h}$. Observation of the slide was performed with a light microscope (Leica LMD7, Leica Microsystems, Buffalo Grove, IL).

\section{Statistical analysis}

We used a Student's t-test to compare total carbohydrates and capsule thickness between the capsulated and thin/non-capsulated isolates.

\section{Abbreviations}

LOS: lipooligosaccharides; PNAG: poly-B-(1-6)-N-acetylglucosamine; HMKP: Hypermucoid string test-positive K. pneumoniae; CAP-AB: Capsulated and mucoid A. baumannii; BHI: Brain heart infusion broth; TEM: Transmission electron microscopy; PBS: Phosphate buffer saline

\section{Acknowledgements}

None

\section{Authors' contributions}

Writing - Original Draft: H.K.; Writing - Review \& Editing: J.L., E. T and Y.C.; Conceptualization: J.L., D. S and Y.C.; Investigation: H.K; Methodology: J.L., D.S., E. T and Y.C.; Formal Analysis: H.K.; Supervision: J.L. All authors have read and approved the manuscript.

\section{Funding}

No funding was received for this research.

\section{Availability of data and materials}

The datasets used and/or analyzed during the current study available from the corresponding author on reasonable request.

\section{Ethics approval and consent to participate}

The study was performed as part of the routine work of the National Center for Antibiotic Resistance and Infection Control, Ministry of Health. No ethics approval or participant consent was required for this study using deidentified isolates.

\section{Consent for publication}

No human subjects were involved in this study.

\section{Competing interests}

Y.C. has received research funding/personal fees from MSD, AstraZeneca, Allecra Therapeutics, DaVoltera, bioMérieux SA, Nariva, Achoagen, Roche, Pfizer, Shionogi, VenatoRx and Qpex Pharmaceuticals. Funders have no role in conducting this research. All authors report no potential conflicts of interest with respect to the research, authorship, and publication of this article.

\section{Author details}

${ }^{1}$ National Institute for Antibiotic Resistance and Infection Control, Ministry of Health, Tel-Aviv Sourasky Medical Center, 6 Weizmann St, 6423906 Tel-Aviv, Israel. ${ }^{2}$ Sackler Faculty of Medicine, Tel-Aviv University, Tel-Aviv, Israel.

Received: 7 June 2020 Accepted: 8 September 2020

Published online: 16 September 2020

\section{References}

1. World Health Organization. Guidelines for the prevention and control of carbapenem-resistant Enterobacteriaceae, Acinetobacter baumannii and Pseudomonas aeruginosa in health care facilities. 2017.

2. Cerqueira GM, Peleg AY. Insights into Acinetobacter baumannii pathogenicity. IUBMB Life. 2011;63:1068-74.

3. Doi Y, Murray GL, Peleg AY. Acinetobacter baumannii: evolution of antimicrobial resistance-treatment options. Semin Respir Crit Care Med. 2015;36:85-98.

4. Weber BS, Harding CM, Feldman MF. Pathogenic Acinetobacter: from the cell surface to infinity and beyond. J Bacteriol. 2016;198:880-7.

5. Singh JK, Adams FG, Brown MH. Diversity and function of capsular polysaccharide in Acinetobacter baumannii. Front Microbiol. 2019;9:3301.

6. Kenyon JJ, Shneider MM, Senchenkova SN, Shashkov AS, Siniagina MN, Malanin SY, et al. K19 capsular polysaccharide of Acinetobacter baumannii is produced via a Wzy polymerase encoded in a small genomic island rather than the KL19 capsule gene cluster. Microbiol (United Kingdom). 2016;162: 1479-89. 
7. Cress BF, Englaender JA, He W, Kasper D, Linhardt RJ, Koffas MAG. Masquerading microbial pathogens. Capsular polysaccharides mimic hosttissue molecules. FEMS Microbiol Rev. 2014;38:660-97.

8. Blumenkrantz N, Asboe-Hansen G. New method for quantitative determination of uronic acids. Anal Biochem. 1973;54:484-9.

9. Domenico P, Salo RJ, Cross AS, Cunha BA. Polysaccharide capsule-mediated resistance to opsonophagocytosis in Klebsiella pneumoniae. Infect Immun. 1994;62:4495-9.

10. Shon AS, Bajwa RPS, Russo TA. Hypervirulent (hypermucoviscous) Klebsiella Pneumoniae: a new and dangerous breed. Virulence. 2013;4:107-18.

11. Geisinger $E$, Isberg RR. Antibiotic modulation of capsular exopolysaccharide and virulence in Acinetobacter baumannii. PLoS Pathog. 2015;11:e1004691.

12. Hu L, Shi Y, Xu Q, Zhang L, He J, Jiang Y, et al. Capsule thickness, not biofilm formation, gives rise to mucoid Acinetobacter baumannii phenotypes that are more prevalent in long-term infections: a study of clinical isolates from a hospital in China. Infect Drug Resist. 2020;13:99-109.

13. Smith HL. A presumptive test for vibrios: the "string" test. Bull World Health Organ. 1970;42:817-8

14. Fang CT, Chuang YP, Shun CT, Chang SC, Wang JT. A novel virulence gene in Klebsiella pneumoniae strains causing primary liver abscess and septic metastatic complications. J Exp Med. 2004. https://doi.org/10. 1084/jem.20030857.

15. Moyes RB, Reynolds J, Breakwell DP. Differential staining of bacteria: gram stain. Curr Protocols Microbiol. 2009:199:697-705.

16. Price CA. Centrifugation in density gradients. Acad Press 2014

17. Menck K, Behme D, Pantke M, Reiling N, Binder C, Pukrop T, et al. Isolation of human monocytes by double gradient centrifugation and their differentiation to macrophages in Teflon-coated cell culture bags. J Vis Exp. 2014;91:e51554.

18. Feltwell T, Dorman MJ, Goulding DA, Parkhill J, Short FL. Separating bacteria by capsule amount using a discontinuous density gradient. J Vis Exp. 2019. https://doi.org/10.3791/58679.

19. Dorman MJ, Feltwell T, Goulding DA, Parkhill J, Short FL. The capsule regulatory network of Klebsiella pneumoniae defined by density-traDISort. MBio. 2018;pii: e01863-e01818.

20. Patrick S, Reid JH. Separation of capsulate and non-capsulate Bacteroides fragilis on a discontinuous density gradient. J Med Microbiol. 1983;16:239-41.

21. Brunner J, Scheres N, El Idrissi NB, Deng DM, Laine ML, Van Winkelhoff AJ, et al. The capsule of Porphyromonas gingivalis reduces the immune response of human gingival fibroblasts. BMC Microbiol. 2010;10:5.

22. Tipton KA, Dimitrova D, Rather PN. Phase-variable control of multiple phenotypes in Acinetobacter baumannii strain AB5075. J Bacteriol. 2015; 197:2593-9.

23. Kawai T. Hypermucoviscosity. An extremely sticky phenotype of Klebsiella pneumoniae associated with emerging destructive tissue abscess syndrome. Clin Infect Dis. 2006:42:1359-61.

24. Lee CH, Liu JW, Su LH, Chien CC, Li CC, Yang KD. Hypermucoviscosity associated with Klebsiella pneumoniae-mediated invasive syndrome: a prospective cross-sectional study in Taiwan. Int J Infect Dis. 2010;14:e688-92.

25. Koeleman JGM, van der Bijl MW, Stoof J, Vandenbroucke-Grauls CMJE, Savelkoul PHM. Antibiotic resistance is a major risk factor for epidemic behavior of Acinetobacter baumannii. Infect Control Hosp Epidemiol. 2001; 22:284-8.

26. Evans BA, Hamouda A, Towner KJ, Amyes SGB. OXA-51-like $\beta$-lactamases and their association with particular epidemic lineages of Acinetobacter baumannii. Clin Microbiol Infect. 2008:14:268-75.

27. Pournaras S, Gogou V, Giannouli M, Dimitroulia E, Dafopoulou K, Tsakris A, et al. Single-locus-sequence-based typing of blaOXA-51-like genes for rapid assignment of Acinetobacter baumannii clinical isolates to international clonal lineages. J Clin Microbiol. 2014;52:1653-7.

28. Smibert RM, Krieg NR. Phenotypic characterization methods for general and molecular bacteriology. In: Methods for General and Molecular Bacteriology. ASM Press, Washington DC. 1994; p 611-654.

29. Dubois M, Gilles KA, Hamilton JK, Rebers PA, Smith F. Colorimetric method for determination of sugars and related substances. Anal Chem. 1956;8:350-6.

30. Brimacombe C, Beatty J. Surface polysaccharide extraction and quantification. BIO-PROTOCOL. 2013; doi: https://doi.org/10.21769/bioprotoc.934.
31. Curry A, Appleton H, Dowsett B. Application of transmission electron microscopy to the clinical study of viral and bacterial infections: present and future. Micron. 2006;37:91-106.

\section{Publisher's Note}

Springer Nature remains neutral with regard to jurisdictional claims in published maps and institutional affiliations.
Ready to submit your research? Choose BMC and benefit from:

- fast, convenient online submission

- thorough peer review by experienced researchers in your field

- rapid publication on acceptance

- support for research data, including large and complex data types

- gold Open Access which fosters wider collaboration and increased citations

- maximum visibility for your research: over $100 \mathrm{M}$ website views per year

At BMC, research is always in progress.

Learn more biomedcentral.com/submissions 